\title{
Investigation on the Effect of Activated Flux on Metal Inert Gas Weldment
}

\author{
Mr. S. Bradeesh Moorthy ${ }^{1}$ \\ ${ }^{1}$ Assistant Professor, \\ Department of Mechanical Engineering, \\ Government College of Technology, Coimbatore, Tamil \\ Nadu, India.
}

\begin{abstract}
Metal Inert Gas welding (MIG) is one of the most conventional welding processes adopted in most of the industries. However, this process is limited by its lower depth of penetration. Thus, it is necessary to modify the conventional process to overcome this incompetence. Activated Flux MIG welding (A-MIG) is an advancement in the field of MIG welding process where in an initial coating of flux is applied in prior to the welding process over the weld surface. This modifies the traditional MIG welding process which is a one step process into two step processes. In A-MIG process, flux is used as purifying agent or flowing agent. The application of flux coating doesn't seem to alter the chemical composition of the weld metals compared to base metals, rather studies show that it increases the penetration rate considerably. This work primarily focusses on the study about influence of coating by titanium oxide, aluminum oxide and iron oxide on the characteristics like weld strength, heat affected zones and depth of penetration.
\end{abstract}

Keywords: Activated Flux, Heat affected zone, Penetration, Weld strength.

\section{I.INTRODUCTION}

Welding is one of the fabrication processes in which same or different materials permanently joined by producing coalescence with or without application of heat and pressure [1]. Metal Inert Gas welding (MIG) works by producing an arc between consumable electrode and workpiece. MIG welding process can be widely used in the automobile and sheet metal applications. Kumar et. al (2016) [2] optimized parameters in the MIG welding process to achieve better quality characteristics using Taguchi method. They suggested that optimal conditions can be applied in the industries like automotive, ship building, etc. Sankar et. al (2018) [3] investigated the influence of process parameters such as weld voltage, weld current and gas flow rate on the weld quality in MIG welding of AISI 310. It is identified that weld current is the dominant factor in affecting the welding process.

\section{ACTIVATED TUNGSTEN INERT GAS WELDING PROCESS}

Activated Tungsten Inert Gas (A-TIG) welding is also traditional method of metal joining in which coating of base plate is carried out to improve the depth of penetration. Ramkumar et.al (2018) [4] revealed that the use of activated flux in the TIG welding of Ti-6Al-4 V results in enhancement in tensile strength of joints and considerable reduction in the impact toughness due to

\author{
Mr. M. Santhosh ${ }^{2}$, Mr. I. Mohamed Akbarali ${ }^{3}$, \\ Mr. B. Premkumar ${ }^{4}$ \\ ${ }^{2,3,4}$ Department of Engineering Design, Government \\ College of Technology, Coimbatore, Tamil Nadu, India.
}

coarse grain structure in the heat affected zone. Chaudhari et.al (2018) [5] uses two various fluxes such as $\mathrm{SiO} 2$, $\mathrm{CrO} 3$ in the activated MIG welding of stainless steel. In addition, they performed optimization of process parameters such as welding speed, current, arc voltage on the weld quality and hardness of weldment. Babbar et.al (2019) [6] presented the influence of flux coating on the penetration depth, micro hardness, tensile strength and metallurgical traits. The experimental design is developed for three factors of current, travel speed and flow rate with three levels. Further, with the aid of radiography it is concluded that defect free welds and tensile tests also showed better quality welds using activated flux technique. Wu Bin et. al (2017) [7] conducted thermal study to determine the changes in welding parameters in A-TIG welding of 309L. Dhindsa et. al (2016) [8] performed design of experiments on A-TIG welding of carbon steel. They found that welding current of 180 Amps and $11 \mathrm{Ltr} . / \mathrm{min}$ shielding gas flow rate resulted in maximum depth of penetration. Magudeeswaran et. al (2014) [9] have selected aspect ratio of ASTM/UNS S32205 for A-TIG welding of DSS joints and performed optimization for maximizing the depth of penetration. Meng et. al (2014) [10] proposed hybrid method for producing high speed welding process. Further, they evaluated weld speed, weld appearance, mechanical and metallurgical property of the TIG-MAG weld joint. Patel et. al (2014) [11] studied effect of $\mathrm{SiO} 2$ and $\mathrm{TiO} 2$ flux on the mechanical properties of austenitic stainless steel. There are few research works have been involved in the study of influencing parameters affecting weld quality of A-TIG welding process [12-13]. Wang et. al (2017) developed numerical model to investigate heat transfer and fluid flow in TIG and A-TIG welding process of stainless steel.

From the detailed research study, it is inferred that there is no such work is performed in the A-TIG welding of mild steel. Hence, the present study involves in determining the effect of titanium oxide, aluminum oxide and iron oxide on the characteristics like weld strength, heat affected zones and depth of penetration.

\section{METHODOLOGY}

The problem associated with the conventional MIG welding process was studied. Literatures were collected based on the topic. Literatures studies showed that 
activated flux TIG welding yielded better results compared to conventional method and hence effect of activated flux was studied in this work. Mild steel was chosen as the parent material as it is cheap and readily available. Three types of fluxes namely, aluminum oxide, iron oxide and titanium oxide were chosen based on the inputs from literature studies. A coating of flux over the parent material was given prior to the welding process and welding was carried out. Tensile and hardness tests were conducted to analyze the mechanical properties of flux coated welds with conventional MIG welding process without flux. The test specimens for tensile and hardness tests were cut using Wire-cut electric discharge machine. Then, the results of the tensile and hardness tests were consolidated and validated.

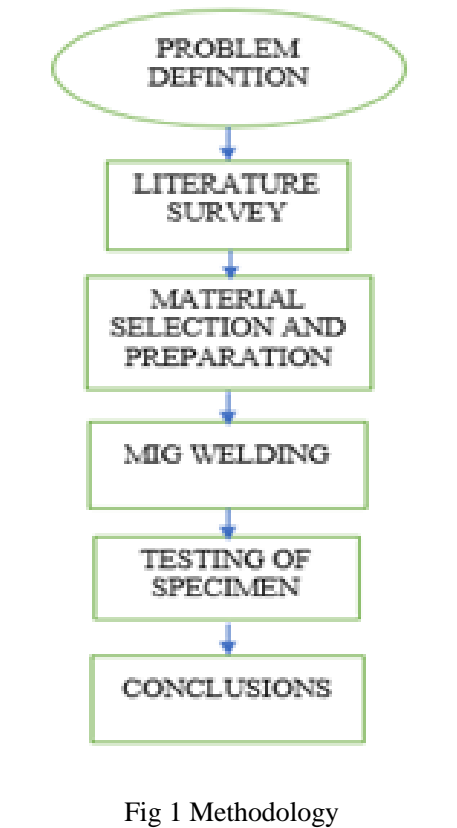

\section{IV.MATERIAL SELECTION AND PREPARATION}

Table 1 Composition of base material

\begin{tabular}{|c|c|c|c|c|c|c|c|c|}
\hline Alloy & $\mathrm{Cr}$ & $\mathrm{Ni}$ & $\mathrm{C}$ & $\mathrm{Mn}$ & $\mathrm{S}$ & $\mathrm{P}$ & $\mathrm{Si}$ & $\mathrm{Fe}$ \\
\hline$\%$ & 0.069 & 0.01 & 0.18 & 0.8 & 0.04 & 0.04 & 0.4 & $\mathrm{Bal}$ \\
\hline
\end{tabular}

Mild steel (MS) was chosen as the base material as it is cheap and readily available. MS plates of thickness $5 \mathrm{~mm}$ and a cross-sectional area of $130 \mathrm{X} 40$ was chosen as the parent material. The fluxes chosen were aluminum oxide (Al2O3), titanium oxide (TiO2) and ferrous oxide (Fe2O3). The activating fluxes can be applied in both manual and mechanized. The flux was mixed with acetone and applied over the surface with a brush prior to welding. The flux can also be made into an aerosol mixture and sprayed over the surface. The figure below shows prepared base material prior to welding.

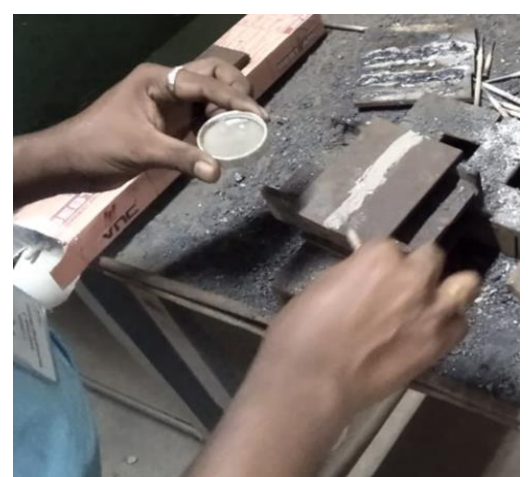

Figure 2 Base material preparation

\section{V.EXPERIMENTATION}

A tack weld was initially placed at the ends of the base materials so that there is no distortion or misalignment of the plates before welding. The MIG welding was then carried out with manual movement of the torch. Care was taken to ensure that a uniform weld bead was being formed. Similarly, the steps were repeated for different flux coatings. The weld specimen was prepared according to ASTM (American Society of Testing of Materials) E8 grade. The dimensions of the test specimen are shown in the figure 3 below

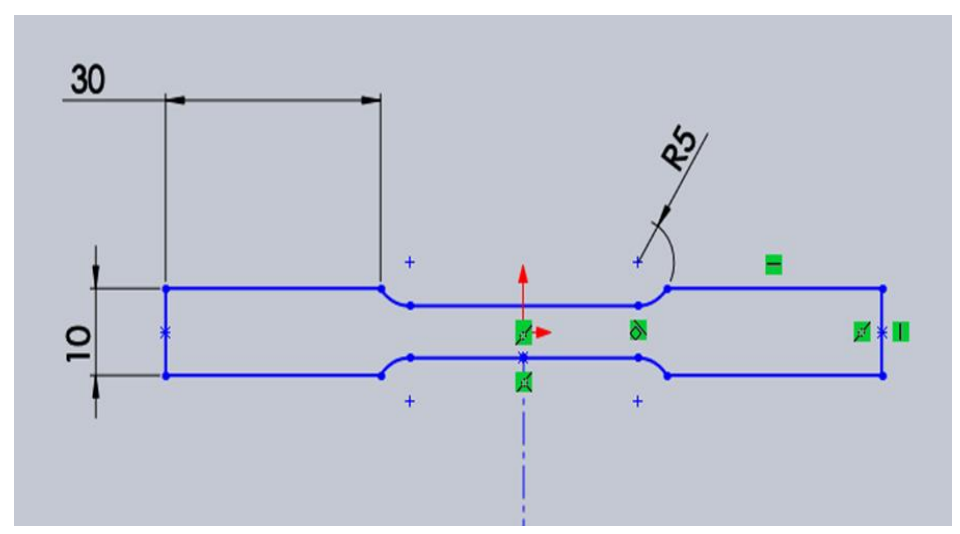

Figure 3 Tensile test specimen dimension

Tensile tests were conducted for five samples, namely ordinary MIG weldment, $\mathrm{Al} 2 \mathrm{O} 3$ coated MIG weldment, Fe2O3 coated MIG weldment and $\mathrm{TiO} 2$ coated MIG weldment and for parent material using Universal Testing Machine facility in the Production Engineering Department of Government College of Technology. It was observed that for ordinary MIG weldment, the necking happened at the center of the weld seam whereas for flux coated MIG weldments necking was found at areas near to the weld seam. 


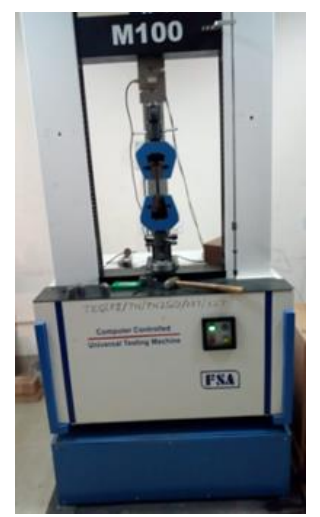

Figure 4 Tensile testing machine

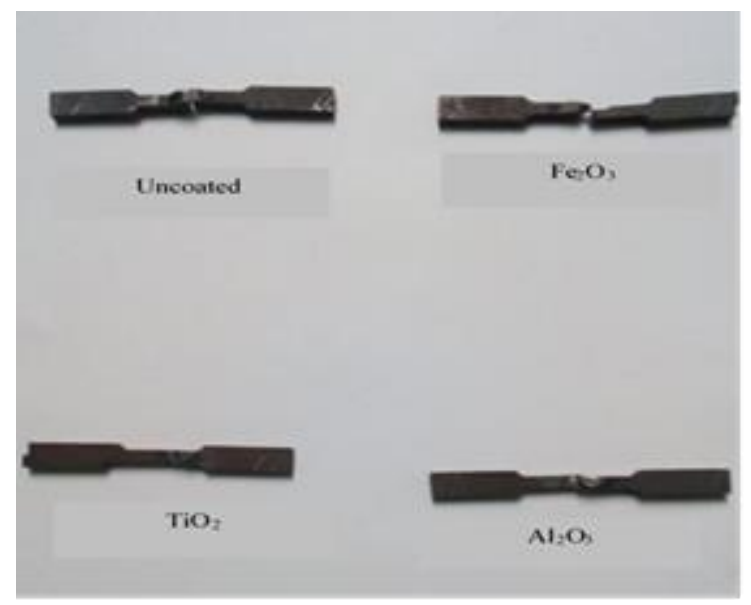

Figure 5 Tensile test specimens after tensile test

Heat Affected Zone in welding refers to a non-melted zone of metal that has experienced changes in its material properties as a result of exposure to high temperatures. The alterations in the material properties are usually a result of welding or high-heat cutting procedures. Hardness test specimens of 10x10 cross sections were prepared. Vickers's hardness tester or diamond indentation was used which was available in Production Engineering Department of Government College of Technology as shown in the figure 6 . The hardness values were measured at three positions near the weld seam. The HV (Hardness in Vicker's scale) were found for three different flux coatings. A sample of hardness test conducted is shown in the figure7.

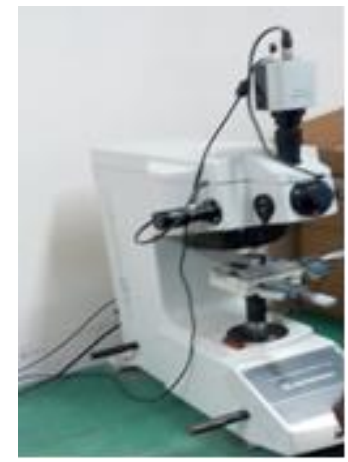

Figure 6 Vickers hardness tester

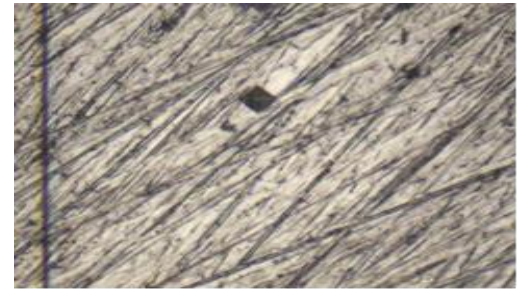

Figure 7 Hardness test sample

\section{VI.RESULTS AND DISCUSSIONS}

Table 2 Comparison of tensile strength between coated and non-coated MIG weldments

\begin{tabular}{|c|c|}
\hline Type of coating applied & $\begin{array}{c}\text { Tensile } \\
\text { strength in } \\
\mathrm{N} / \mathrm{mm}^{2}\end{array}$ \\
\hline Parent material with no coating & 312 \\
\hline Ordinary MIG weld with no coating & 46.429 \\
\hline $\mathrm{Fe}_{2} \mathrm{O}_{3}$ coated MIG weld & 93.543 \\
\hline $\mathrm{Al}_{2} \mathrm{O}_{3}$ coated MIG weld & 115.171 \\
\hline
\end{tabular}

It is seen from table 1 that coated MIG weldments showed significant increase in the tensile strength than noncoated weldments. The below figure shows comparison of hardness values of coated and non-coated weldments. The increase in hardness value near to the center indicates the heat affected zone presence.

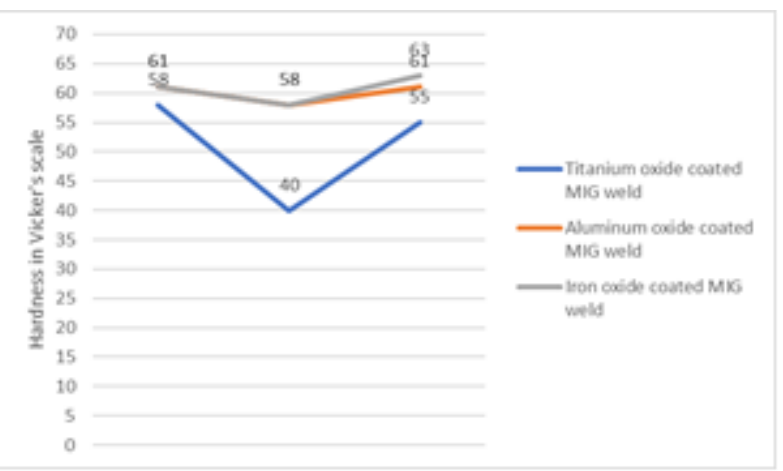

Figure 8 Comparison of hardness values for coated and non-coated weldments

Titanium oxide coted MIG weld showed better results compared to aluminum oxide and iron oxide coated welds. This study can be further extended by performing dynamic analysis including fatigue life analysis for titanium oxide coated MIG weldments.

Aluminum and Iron oxide coated MIG weldments didn't show any gradual decrease in the hardness value which is an indirect measure of the heat affected zone.

\section{VII.CONCLUSIONS}

From the tensile test results, it can be seen that ordinary MIG welding without the application of flux showed very less tensile strength compared to the flux coated weldments. The very less tensile strength of the MIG weld without coating could be attributed with the presence of many voids 
and pores associated with manual welding techniques. $\mathrm{TiO} 2$ coated MIG weld was found to have the highest tensile strength after parent material. Hardness test results showed the influence of HAZ on the weldments. The hardness value seems to increase while moving from the center of the weld. In case of MIG weld without coating, necking was found to happen at the centre of the weld whereas in case of other flux coated MIG welds, necking was found to happen at the regions closer to the centre of the weld. These results obtained surely indicated the influence of flux on ordinary MIG weld without the application of flux while welding

\section{REFERENCES}

[1] Weman, K., \& Lindén, G. (Eds.). (2006). MIG welding guide. Woodhead Publishing.

[2] Kumar, A., Khurana, M. K., \& Yadav, P. K. (2016). 'Optimization of gas metal arc welding process parameters. In IOP Conference Series: Materials Science and Engineering', (Vol. 149, No. 1, p. 012002). IOP Publishing.

[3] Sankar, B. V., Lawrence, I. D., \& Jayabal, S. (2018). 'Experimental study and analysis of weld parameters by GRA on MIG welding. Materials Today: Proceedings', 5(6), 14309-14316.

[4] Ramkumar, K. D. et al. (2018) 'Effect of activated flux on penetration depth, microstructure and mechanical properties of Ti-6Al-4V TIG welds', Journal of Materials Processing Technology, 261, pp. 233-241. doi: 10.1016/j.jmatprotec.2018.06.024

[5] Chaudhari, P. G., Patel, P. B. and Patel, J. D. (2018) 'Evaluation of MIG welding process parameter using Activated Flux on SS316L by AHP-MOORA method', Materials Today: Proceedings. Elsevier Ltd, 5(2), pp. 5208-5220. doi: 10.1016/j.matpr.2017.12.103.

[6] Babbar Atul.et al. (2019), 'Enhancement of activated tungsten inert gas welding using multi-component $\mathrm{TiO}_{2}-\mathrm{SiO}_{2}-\mathrm{Al}_{2} \mathrm{O}_{3}$ hybrid flux'. Measurement.

doi: https://doi.org/10.1016/j.measurement.2019.106912

[7] Wu, B. et al. (2018) 'Effect of active fluxes on thermophysical properties of 309L stainless-steel welds', Journal of Materials Processing Technology. Elsevier B.V., 255(2010), pp. 212-218. doi: 10.1016/j.jmatprotec.2017.12.018.

[8] Dhindsa, G. S. et al. (2016) 'Effect of Activated Tig Welding Process on Depth of Penetration in carbon steel (SA516 GR -70)', II(Xi), pp. 727-733

[9] Magudeeswaran, G. et al. (2014) 'Optimization of process parameters of the activated tungsten inert gas welding for aspect ratio of UNS S32205 duplex stainless-steel welds', Defence Technology. Elsevier Ltd, 10(3), pp. 251-260. doi: 10.1016/j.dt.2014.06.006.

[10] Meng, X. et al. (2014) 'High speed TIG-MAG hybrid arc welding of mild steel plate', Journal of Materials Processing Technology. Elsevier B.V., 214(11), pp. 2417-2424. doi: 10.1016/j.jmatprotec.2014.05.020.

[11] Patel, A. B. and Patel, P. S. P. (2014) 'The Effect of Activating Flux in Tig Welding', International Journal of Computational Engineering Research, 4(1), pp. 65-70.

[12] Singh, A. K., Dey, V. and Rai, R. N. (2017) 'Techniques to improve weld penetration in TIG welding (A review)', Materials Today: Proceedings. Elsevier Ltd, 4(2), pp. 1252-1259. doi: 10.1016/j.matpr.2017.01.145

[13] Vidyarthy, R. S. and Dwivedi, D. K. (2016) 'Activating flux tungsten inert gas welding for enhanced weld penetration', Journal of Manufacturing Processes. The Society of Manufacturing Engineers, 22, pp. 211-228. doi: 10.1016/j.jmapro.2016.03.012.

[14] Wang, X. et al. (2017) 'Investigation of heat transfer and fluid flow in activating TIG welding by numerical modeling', Applied Thermal Engineering, 113, pp. 27-35. 